\section{Non Angiographic Prediction of Coronary Artery Disease in Obese Patients with Prominent Thick Layer of Pericardial Fat: A Case Report}

\section{Zainab Alsharef, Safia Inam, Mohammed H Lhmdi, Amr W} Aljareh, Hassan Balubid and Walid Hassan*

Department of Cardiovascular Disease, International Medical center, Jeddah, Saudi Arabia

\begin{abstract}
In this report, we present a case of middle aged obese women with no coronary artery disease risk factors, who presented with recurrent angina and was admitted for work up and possible coronary intervention. During the work up we found that the patient has a prominent thick layer of pericardial pad of fat. The patient underwent coronary angiogram and percutaneous coronary intervention with angioplasty and coronary stent. We believe and also as shown in previous studies that the thickness of this layer could correlate with the coronary artery disease and can be used for risk stratification.
\end{abstract}

\section{Introduction}

Epicardial fat is in direct contact with coronary arteries. Pericardial fat is the visceral fat of the heart deposited under the visceral layer of the pericardium and has the same origin as abdominal visceral fat, which is shown to be strongly related to the development of Coronary Artery Disease (CAD) [1]. The accumulation of epicardial and pericardial fat is known to be a rich source of free fatty acids and a number of inflammatory cytokines [1-3]. Inflammatory mediators that originate in vascular and extravascular tissues promote metabolic syndrome and coronary lesion formation. Adipose tissue may function as an endocrine organ that contributes to an inflammatory burden in patients at risk of cardiovascular complications.

Transthoracic echocardiogram can measure the subepicardial adipose tissue on the free wall of right ventricle at end-diastole from parasternal long- and short-axis views of three cardiac cycles $[4,5]$.

${ }^{*}$ Corresponding author: Walid Hassan, Department of Cardiovascular Disease, International Medical center, Jeddah, Saudi Arabia, Tel: + 966 126509000; Fax: + 966 126509789; E-mail: whassan@imc.med.sa

Citation: Alsharef Z, Inam S, Lhmdi MH, Aljareh AW, Baludid H, et al. (2016) Non Angiographic Prediction of Coronary Artery Disease in Obese Patients with Prominent Thick Layer of Pericardial Fat: A Case Report. J Diabetes Metab Disord 3: 014.

Received: May 28, 2016; Accepted: July 08, 2016; Published: July 22, 2016

Copyright: (C) 2016 Alsharef Z, et al., This is an open-access article distributed under the terms of the Creative Commons Attribution License, which permits unrestricted use, distribution, and reproduction in any medium, provided the original author and source are credited.
Herein we present a case of 48 year-old with pericardial fat pad and coronary artery disease.

\section{Case Presentation}

A 48 years old female obese patient non smoker, non diabetic, non hypertensive and no other coronary artery disease risk factors, she had cardiac angiography 2 years ago for chest pain revealed normal coronary arteries. She presented to the outpatient clinic with recurrent angina increasing for the last 2 months, so performed nuclear stress test which showed mild anteroseptal ischemia (Figure 1) and was kept on anti ischemic treatment. She continued to have recurrent chest pain so was admitted 7 months later for coronary angiogram and possible coronary intervention.

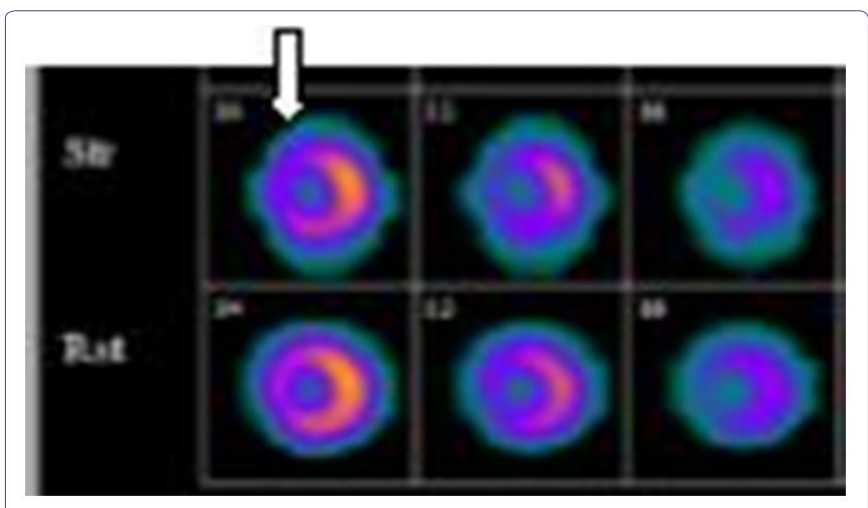

Figure 1: Nuclear Stress Test (Mild Anteroseptal Ischemia).

Vital signs: Blood pressure 111/64 mmHg, pulse rate 75 beat/minute, height $160 \mathrm{~cm}$, weight $109 \mathrm{~kg}$ (BMI 38.5).

Cardio vascular system: normal S1S2 no added sound and no mummer, Chest: good air entry bilaterally with no added sound, Abdomen: soft, lax, lower extremities: lipodema.

Laboratory investigations showed normal complete blood cell count \& renal function and lipid profile test. Initial high sensitivity C-Reactive Protein (hs-CRP) was elevated $9.9 \mathrm{mg} / \mathrm{ml}$ (normal <5) and in follow up normalized $4.0 \mathrm{mg} / \mathrm{l}$.

Electrocardiography showed normal sinus rhythm and heart rate 67 beat/minute and nonspecific anterior ST-T changes.

Chest $\mathrm{x}$-ray showed well defined faint large opacity/shadow project over the right paracardiac and cardiophrenic angle area composed of thickened wing like most likely presenting prominent pericardial fat pad (Figure 2), CT Chest was done and showed exaggerated pericardial fat (Figure 3), Epicardial fat measured $8 \times 4 \mathrm{~cm}$ in thickness, abdominal CT showed fatty liver.

Echocardiography showed prominent thick layer of pericardial pad of fat with no other significant abnormalities (Figure 4).

She underwent cardiac angiography which showed: left main: mild plaque; Left Anterior Descending (LAD): proximal mid 70\% and mid 80-90\% stenosis (Figure 5), left circumflex artery: mid 30\%, right coronary artery: mid $30 \%$. So successful direct stenting was done 
Citation: Alsharef Z, Inam S, Lhmdi MH, Aljareh AW, Baludid H, et al. (2016) Non Angiographic Prediction of Coronary Artery Disease in Obese Patients with Prominent Thick Layer of Pericardial Fat: A Case Report. J Diabetes Metab Disord 3: 014.

- Page 2 of $3 \cdot$

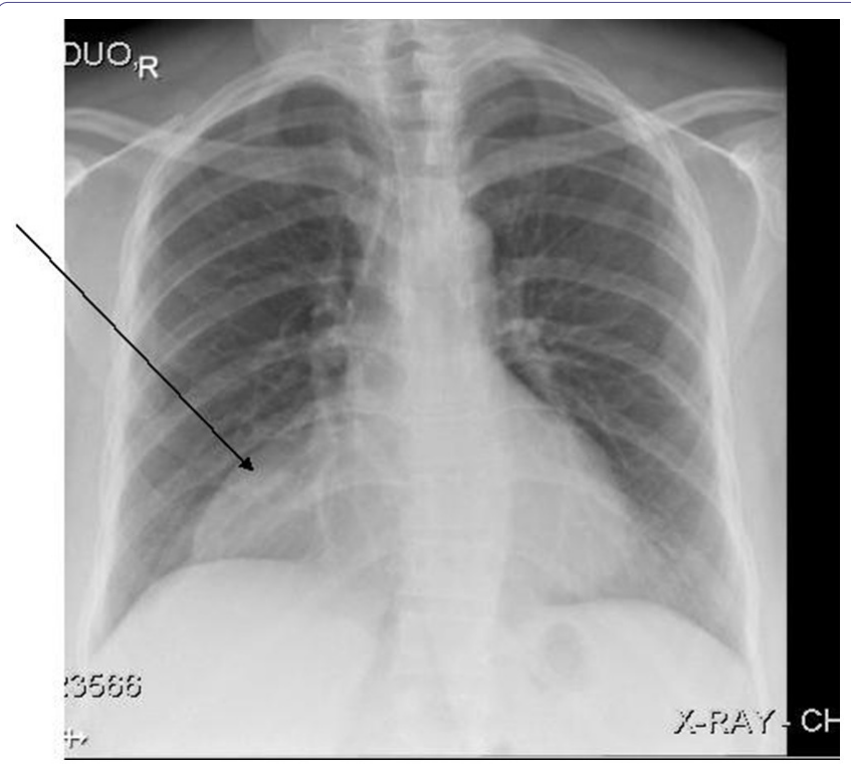

Figure 2: Chest $\mathrm{x}$ ray (Large shadow over the right paracardiac and cardiophrenic angle).

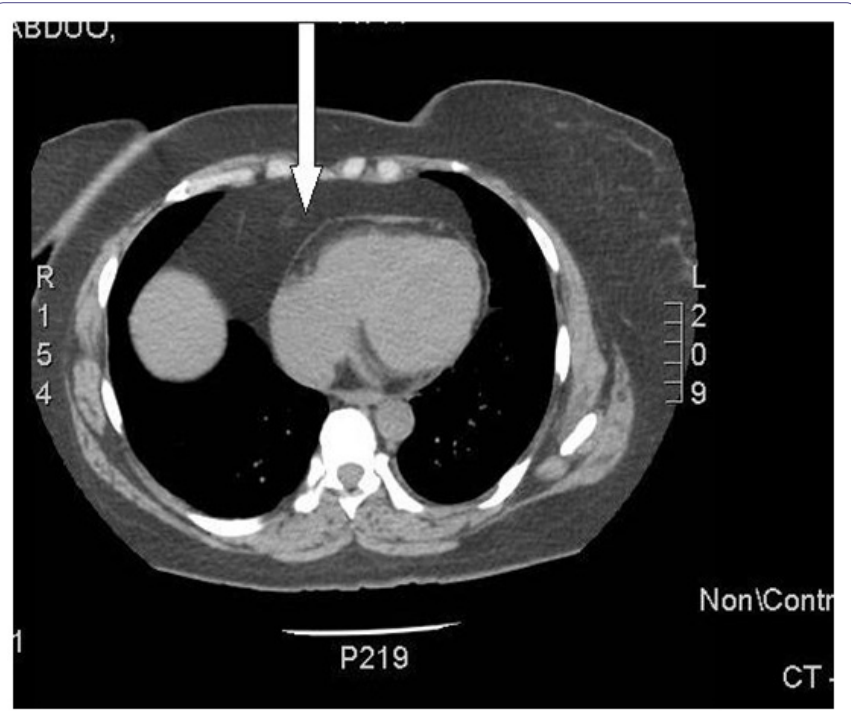

Figure 3: Chest CT scan (Fat).

to left anterior descending with 2 stents (Figure 6), the patient tolerated the procedure well without any complication. The patient transferred to floor for 24 hour observation, she did well and She was discharged on the following medications: Acetylsalicylic acid $81 \mathrm{mg}$ daily, Clopidegrol $75 \mathrm{mg}$ daily, Atrovastatin 20 daily, Metoprolol 50 $\mathrm{mg}$ daily, Perindopril $5 \mathrm{mg}$ daily. She has been followed up in cardiology clinic for 8 months so far and asymptomatic.

\section{Discussion}

Many studies showed that the pericardial adipose tissue measurement could be used as a quantitative indicator of metabolic disorders and systemic atherosclerosis and also as a key for CAD risk stratification. Inflammatory mediators that originate in vascular and extravascular tissues promote coronary lesion formation. Adipose tissue may function as an endocrine organ that contributes to an inflammatory burden in patients at risk of cardiovascular complications Previous studies examined the expression of J Diabetes Metab Disord ISSN: 2381-201X, Open Access Journal

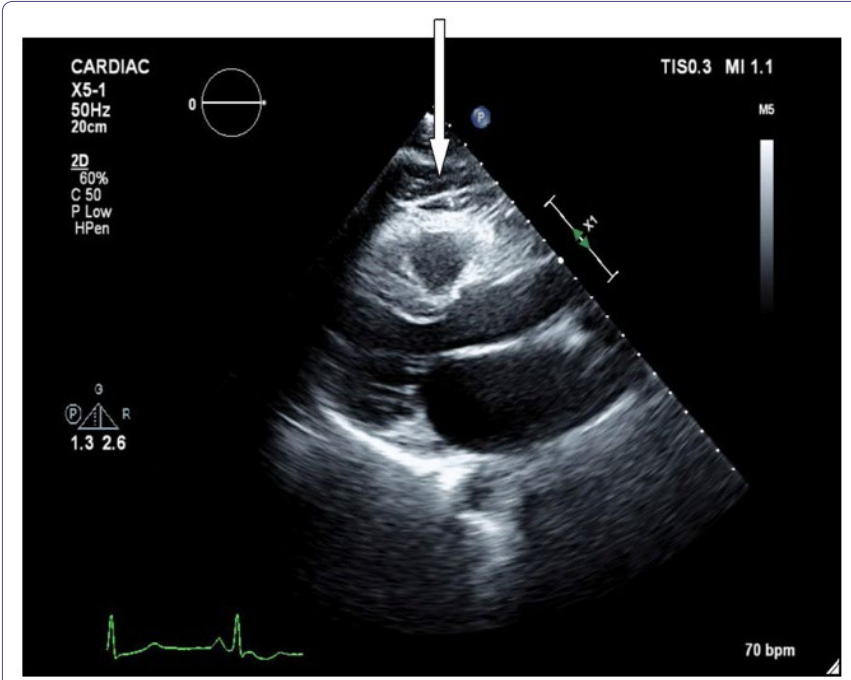

Figure 4: Echocardiogram (Fat).

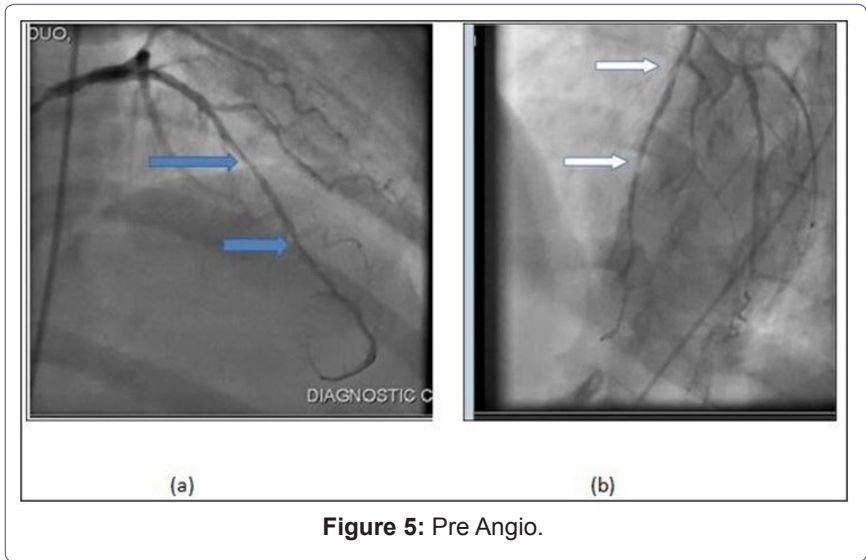

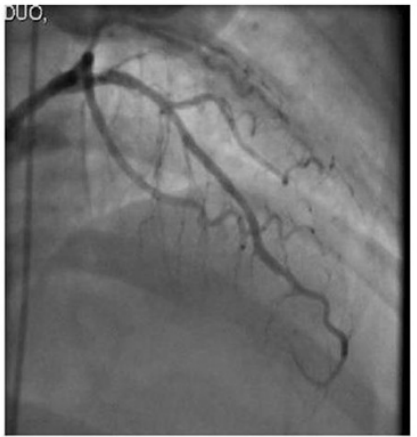

(a)

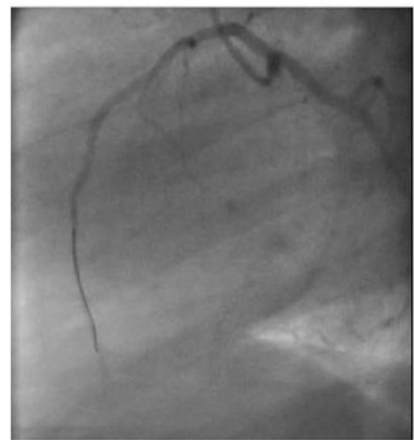

(b)
Figure 6: Post Angio.

inflammatory mediators in epicardial and subcutaneous adipose stores in patients with critical CAD where samples were taken at the outset of elective coronary bypass surgery, showed higher levels of chemokine (Monocyte Chemotactic Protein [MCP]-1) and inflammatory cytokines (Interleukin [IL]-1beta, IL-6, and Tumor Necrosis Factor [TNF]-alpha) and protein were observed in epicardial adipose stores. These proinflammatory properties of epicardial adipose tissue were noted irrespective of clinical variables (diabetes, body mass index, and chronic use of statins or ACE inhibitors/angiotensin II receptor blockers) or plasma concentrations of circulating biomarkers [1-3].

Volume $3 \cdot$ Issue $2 \cdot 100014$ 
Our case report supports this association as our obese patient with recurrent chest pain who developed significant LAD artery disease over 2 years period and she underwent coronary angioplasty and stents implantation, and after investigations was found to have very thick pericardial fat as shown on the chest $\mathrm{x}$ ray, echocardiogram and chest CT scan.

Other ways to measure pericardial and visceral fat include; waist-hip ratio, BMI, Dexa scan of visceral fat, and MRI of visceral fat need to be compared in a large study to determine the best modality for CAD risk stratification in obese patients [6].

\section{Conclusion}

Epicardial adipose tissue is a source of several inflammatory mediators in high-risk cardiac patients. We believe that the thickness of this layer could correlate with the coronary artery disease and can be used for risk stratification.

\section{References}

1. Mazurek T, Zhang L, Zalewsky A, Mannion JD, Diehl JT, et al. (2003) Human epicardial adipose tissue is a source of inflammatory mediators. Circulation 108: $2460-2466$.
2. lacobellis G, Pistilli D, Gucciardo M, Leonetti F, Miraldi F, et al (2005) Adiponectin expression in human epicardial adipose tissue in vivo is lower in patients with coronary artery disease. Cytokine 29: 251-255.

3. Baker AR, Silva NF, Quinn DW, Hartle AL, Pagano D, et al. (2006) Human epicardial adipose tissue expresses a pathogenic profile of adipocytokines in patients with cardiovascular disease. Cardiovasc Diabetol 5: 1.

4. Chaowalit N, Somers VK, Pellikka PA, Rihal CS, Lopez-Jimenez F (2006) Subepicardial adipose tissue and the presence and severity of coronary artery disease. Atherosclerosis 186: 354-359.

5. Shemirani H, Hosseini K (2004) The relationship between echocardiographic epicardial fat thickness and coronary artery disease. Journal of Isfahan Medical School 21: 35-37.

6. Lewington S, Clarke R, Qizilbash N, Peto R, Collins R, et al. (2002) Age-specific relevance of usual blood pressure to vascular mortality: A meta-analysis of individual data for one million adults in 61 prospective studies. Lancet 360: 1903-1913. 